\title{
Development of a Method for Converting a TAK1 Type I Inhibitor into a Type II or c-Helix-Out Inhibitor by Structure-Based Drug Design (SBDD)
}

\author{
Terushige Muraoka, ${ }^{*}, a$ Mitsuaki Ide, ${ }^{a}$ Machiko Irie, ${ }^{b}$ Kenji Morikami, ${ }^{a}$ Takaaki Miura,${ }^{b}$ \\ Masamichi Nishihara, ${ }^{a}$ and Hirotaka Kashiwagi ${ }^{a}$ \\ ${ }^{a}$ Research Division, Chugai Pharmaceutical Co., Ltd.; 1-135 Komakado, Gotemba, Shizuoka 412-8513, Japan: and \\ ${ }^{b}$ Research Division, Chugai Pharmaceutical Co., Ltd.; 200 Kajiwara, Kamakura, Kanagawa 247-8530, Japan. \\ Received July 28, 2016; accepted August 29, 2016
}

We have developed a method for converting a transforming growth factor- $\beta$-activated kinase 1 (TAK1) type I inhibitor into a type II or c-helix-out inhibitor by structure-based drug design (SBDD) to achieve an effective strategy for developing these different types of kinase inhibitor in parallel. TAK1 plays a key role in inflammatory and immune signaling, and is therefore considered to be an attractive molecular target for the treatment of human diseases (inflammatory disease, cancer, etc.). We have already reported novel type I TAK1 inhibitor, so we utilized its X-ray information to design a new chemical class type II and c-helixout inhibitors. To develop the type II inhibitor, we superimposed the X-ray structure of our reported type I inhibitor onto a type II compound that inhibits multiple kinases, and used SBDD to design a new type II inhibitor. For the TAK1 c-helix-out inhibitor, we utilized the X-ray structure of a b-Raf c-helix-out inhibitor to design compounds, because TAK1 is located close to b-Raf in the Sugen kinase tree, so we considered that TAK1 would, similarly to b-Raf, form a c-helix-out conformation. The X-ray crystal structure of the inhibitors in complex with TAK1 confirmed the binding modes of the compounds we designed. This report is notable for being the first discovery of a c-helix-out inhibitor against TAK1.

Key words transforming growth factor- $\beta$-activated kinase 1 (TAK1); inhibitor; type I; type II; c-helix-out; structure-based drug design

Of over 500 kinases in human that maintain the functions of cells, ${ }^{1)}$ it is not completely clear which kinase inhibition causes an adverse event; therefore, it is important for kinase inhibitors to have a highly selective profile. However, in many cases, kinase inhibitors possess undesired off-target kinase activity, so multiple development candidates with different kinase selectivity profiles need to be prepared, and then a compound with a wide therapeutic window that has no severe adverse effects can be selected as a development candidate. In general, kinase inhibitors are classified into three different types $^{2,3)}$ : a type I inhibitor binds to the active conformation (DFG-in conformation) of a kinase at the ATP-binding site and competes with ATP; a type II inhibitor binds to both the ATP binding site and its adjacent binding pocket in an inactive conformation (DFG-out conformation) of a kinase; a type III inhibitor is an allosteric inhibitor that has a binding site distinct from the ATP-binding site. Discovery of a type I inhibitor with high kinase selectivity is additionally challenging because amino acid residues in the ATP-binding site are highly conserved in many kinases. On the other hand, it is considered easier to identify a selective type II inhibitor because a type II inhibitor is able to utilize the lipophilic binding pocket derived from the DFG-out conformation, which is less conserved in terms of amino acid residues (though it has recently been reported that not all type II inhibitors possessed high kinase selectivity, ${ }^{4}$ so this topic is currently under discussion). In the case of type III inhibitor, high target kinase selectivity can be expected because the binding site is outside of the ATP-binding site, and conservation of the amino acid residues in this site is low (as shown, for example, by mitogen-acti- vated protein kinase/extracellular signal regulated kinase 1/2 (MEK 1/2) kinase inhibitors). ${ }^{3)}$ In short, from the aspect of kinase selectivity, both type II and type III inhibitors are superior to a type I inhibitor, but the majority of kinase inhibitors that have been developed are type I inhibitors, since it is difficult to obtain either type II or type III hit compounds from a HTS screening. Very recently, a new type of kinase inhibitor, the c-helix-out inhibitor, has been reported, which binds at the ATP-binding site in the DFG-in conformation and shifts the c-helix loop of a kinase to form a new lipophilic pocket in the so-called "c-helix-out conformation." ${ }^{5-10)}$ Once obtained, this type of inhibitor would have outstanding selectivity, because few kinases are known to possess this rare binding mode, and in fact the U.S. Food and Drug Administration (FDA)approved c-helix-out inhibitors developed so far have highly selective kinase profiles. ${ }^{5,10}$ ) Therefore, we consider that preparing these different types simultaneously would be an effective strategy for developing a kinase inhibitor.

Transforming growth factor- $\beta$-activated kinase 1 (TAK1) is a serine/threonine kinase that plays a pivotal role in inflammatory and immune signaling. TAK1 was discovered by Matsumoto et al. as a mitogen-activated kinase kinase kinase (MAP3K) activated by transforming growth factor- $\beta$ (TGF$\beta),{ }^{11)}$ and since then has been elucidated as a mediator of multiple cytokines such as tumor necrosis factor-alpha (TNF- $\alpha$ ), interleukin-1 (IL-1), lipopolysaccharide (LPS), etc. ${ }^{12-14)}$ TAK1 exerts its activity only when it forms complexes with its activator proteins TAB1 and TAB2 or TAB3. ${ }^{15-17)}$ TAB1 binds to TAK1 at the N-terminal domain, while either TAB2 or TAB3 binds to TAK1 at the C-terminal domain. TAK1 phos- 


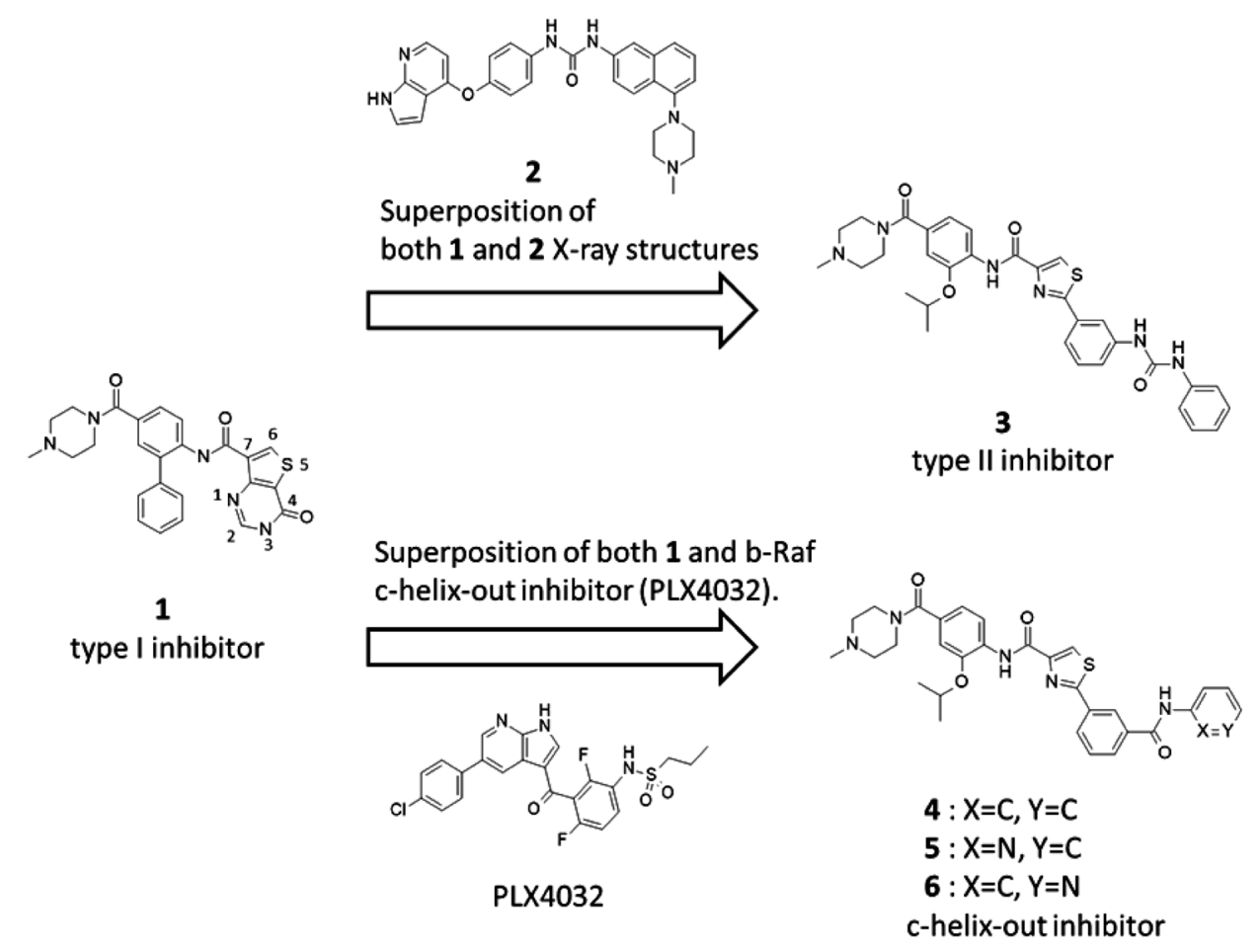

Fig. 1. Outline of Our Conversion Method from a Type I Inhibitor (1) into Designed Type II (3) and c-Helix-Out Inhibitors (4-6)

phorylates downstream kinases, such as the mitogen-activated kinase kinase (MKK) family (MKK3/4/6/7), p38, c-Jun N-terminal kinase $(\mathrm{JNK})$, and the inhibitor of kappa B ( $\mathrm{k} \kappa \mathrm{B})$ kinase (IKK) family (IKK $\alpha$, IKK $\beta$ and NEMO), to activate transcription factors, such as activation protein-1 (AP-1) and nuclear factor $-\kappa \mathrm{B}(\mathrm{NF}-\kappa \mathrm{B})$, that regulate stress response, immunity, inflammation and cancer signaling. Indeed, p38 and IKK have been developed as targets for rheumatoid arthritis and airway inflammation, ${ }^{18)}$ and systemic administration of TAK1 small interfering RNA (siRNA) particles has been shown to alleviate inflammation in a mouse model of immune-mediated inflammatory disorder. ${ }^{19)}$ In summary, TAK1 is considered to be an attractive molecular target for the treatment of human diseases (inflammatory disease, cancer, etc.).

In this report, we describe using structure-based drug design (SBDD) to convert a type I inhibitor into type II and c-helix-out inhibitors in parallel (Fig. 1). We have already reported novel type I TAK1 inhibitors and X-ray information between one of the most potent our TAK1 type I inhibitor (1) and TAK1 (PDB code: 5JGA), ${ }^{20)}$ we utilized this information to design a new type II inhibitor (3) and c-helix-out inhibitors $(\mathbf{4}, \mathbf{5}$, and $\mathbf{6})$ by the hybridization strategy. ${ }^{21,22)}$ For the type II inhibitor, the X-ray crystal structure of $\mathbf{1}$ and $\mathbf{2}$ were superimposed to design compound $\mathbf{3}$ by modeling. Because we had obtained a type II TAK1 binder, biaryl urea compound 2 (TAK1 $K_{\mathrm{d}}=12 \mathrm{nM}$ ) by surface plasmon resonance (SPR) screening. In addition, fortunately we obtained this co-crystal between compound $\mathbf{2}$ and TAK1 in the DFG-out conformation and were able to utilize this X-ray structure information, while compound $\mathbf{2}$ was a multi kinase inhibitor (manuscript was preparing). Therefore we conducted this scaffold hopping approach to create a new chemical class of TAK1 type II inhibitor. On the other hand, to develop TAK1 c-helix-out inhibitors we utilized the X-ray structure of the b-Raf c-helixout inhibitor PLX4032, ${ }^{23)}$ and designed compounds 4, 5, and
6, because in the Sugen kinase tree ${ }^{1)}$ TAK1 is located close to b-Raf, so we considered TAK1 was similar to b-Raf and consequently TAK1 would also form a c-helix-out conformation. The binding mode of our designed compounds was confirmed by the X-ray crystal structure of the inhibitors in complex with TAK1; 3 bound to TAK1 with DFG-out as a type II inhibitor, whereas 4 bound to TAK1 with DFG-in and shifted the c-helix loop as a c-helix-out inhibitor. We expected both 5 and $\mathbf{6}$ would also be c-helix-out inhibitors because their binding conformation in TAK1 would be very similar to compound 4. This report is notable for the discovery of a chelix-out inhibitor against TAK1. We consider these converting methods would be adapted to other kinases and form the basis of an effective strategy for kinase inhibitor development by preparing these different types simultaneously.

\section{Chemistry}

The synthesis of type II inhibitor 3 and c-helix-out inhibitors $\mathbf{4}, \mathbf{5}$, and $\mathbf{6}$ is shown in Chart 1 . The starting material 7 was prepared by the same procedure in our previously report. ${ }^{20}$ Then the common intermediate 8 was synthesized by amidation reaction between 7 and commercially available 2-bromothiazole-4-carboxylic acid in $83 \%$ yield. To synthesize compound 9, Suzuki coupling between $\mathbf{8}$ and $m$-aminophenylboronic acid ${ }^{24)}$ was conducted to afford 9, and then the obtained compound 9 was treated with phenylisocyanate at $60^{\circ} \mathrm{C}$ to generate the type II inhibitor 3 as an urea compound in moderate yield ( 2 steps $39 \%$ ). Alternatively, to synthesize compounds 4, 5, and 6 as c-helix-out inhibitors, Suzuki coupling between compound $\mathbf{8}$ and $m$-(methoxycarbonyl)phenylboronic acid was performed, and a hydrolysis reaction was executed to afford carboxylic acid 10. Subsequently, an amidation reaction with aniline, 2-aminopyridine, or 3-aminopyridine generated c-helix-out compounds in good yield (3 steps 50, 48, and $69 \%$, respectively). 

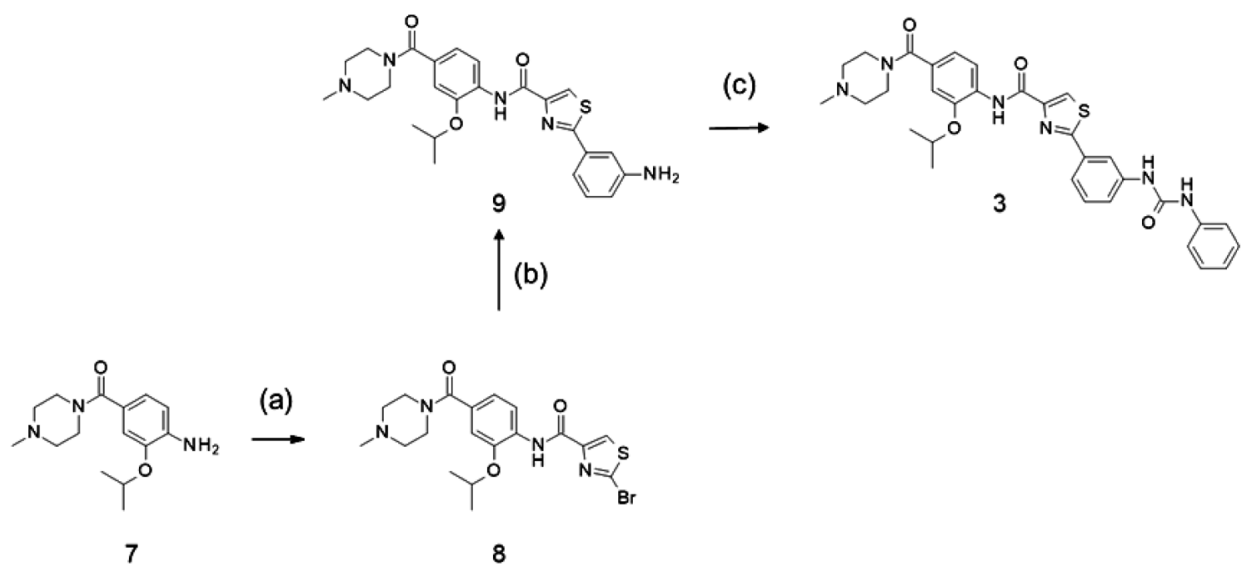

(a)
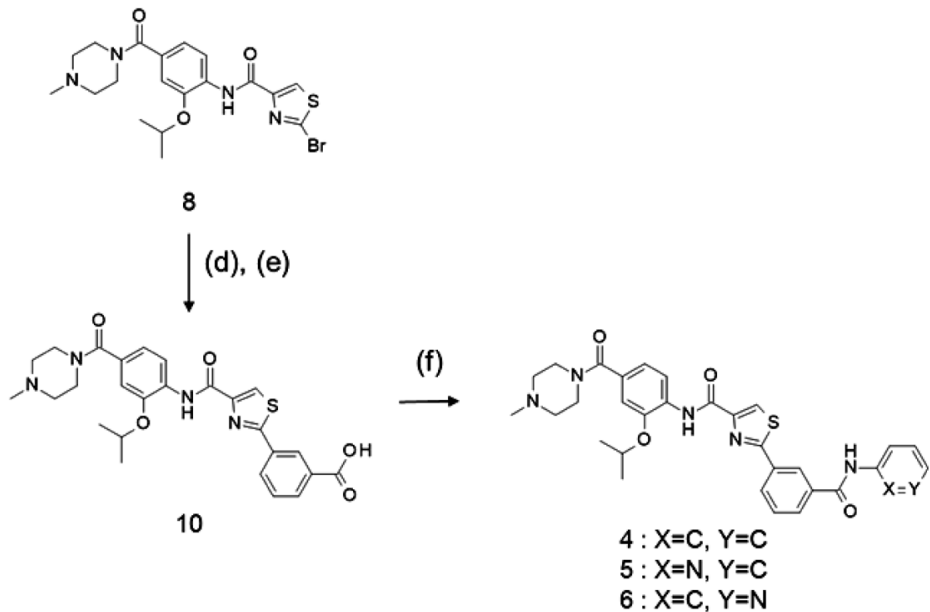

Reagents and conditions: (a) 2-Bromothiazole-4-carboxylic acid, HATU, DIPEA, acetonitrile, room temperature, 83\%; (b) $m$-Aminophenylboronic acid, Pd(OAc), SPhos, $\mathrm{K}_{3} \mathrm{PO}_{4}$, toluene, $100^{\circ} \mathrm{C}, 51 \%$; (c) Phenylisocyanate, THF, $60{ }^{\circ} \mathrm{C}, 76 \%$; (d) $m$-(Methoxycarbonyl)phenylboronic acid, $\mathrm{Pd}(\mathrm{OAc}){ }_{2}, \mathrm{~S}-\mathrm{Phos}, \mathrm{K}_{3} \mathrm{PO}{ }_{4}$, toluene, $100{ }^{\circ} \mathrm{C}, 85 \%$; (e) $2 \mathrm{~N} \mathrm{LiOH} \mathrm{aq.,} \mathrm{THF,} \mathrm{quant.;} \mathrm{(f)} \mathrm{Aniline,} \mathrm{2-aminopyridine,} \mathrm{or} \mathrm{3-aminopyridine,} \mathrm{HATU,} \mathrm{DIPEA,} \mathrm{solvent,} \mathrm{4:} \mathrm{59 \% ,} \mathrm{5:} 57 \%$, and 6: $81 \%$.

Chart 1. Synthesis of Type II Inhibitor $\mathbf{3}$ and c-Helix-Out Inhibitors 4, 5, and $\mathbf{6}$

\section{Results and Discussion}

The first conversion process from a TAK1 type I inhibitor into a type II was achieved by superimposing the X-ray structure of compound $\mathbf{1}$ in TAK1 over that of compound 2 in TAK1. We had already reported novel TAK1 type I inhibitors with their X-ray information, including the complex of 1 (TAK1 $\mathrm{IC}_{50}=2.3 \mathrm{~nm}$ ) with TAK1 in the DFG-in conformation $^{20)}$ (Fig. 2(a)). Additionally, we had obtained a type II TAK1 binder, biaryl urea compound 2 (TAK1 $K_{\mathrm{d}}=12 \mathrm{~nm}$ ) with multi-kinase inhibitory activity (Journal of Biomolecular Screening, submmited); therefore, we tried to gain the co-crystal of $\mathbf{2}$ with TAK1 in the DFG-out conformation and reveal binding mode of $\mathbf{2}$ in TAK1. (Recently researchers from two different groups have revealed X-ray structures in which a ligand binds to TAK1 in the DFG-out conformation, ${ }^{25,26)}$ but this information was not available at the beginning of this study.) Fortunately, we obtained this co-crystal and were able to utilize this X-ray structure information (Fig. 2(b)). Firstly, we described the binding mode of 1 with TAK1 in the DFG-in conformation utilizing the X-ray information (Fig. 2(a)) and found that the distance from an amide carbonyl group at 7-position of the thienopyrimidinone part of $\mathbf{1}$ to Ala107 in the hinge position was $2.7 \AA$, which created a hydrogen bonding interaction with TAK1 in this region. Moreover, the distance from carbonyl group at 4-position of thienopyrimidinone near the DFG loop to crystal water was $2.6 \AA$, and the distance from the crystal water to the side chain of Glu77 and the backbone amide NH of Asp175 (DFG) was 2.7 and $2.9 \AA$, respectively, which meant that this carbonyl group of thienopyrimidinone had tight interactions with the side chain of Glu77 and with Asp175 by hydrogen bonding via a crystal water, with desirable effects on the potent inhibi- tory TAK1 activity. Next, we elucidated another interaction between 1 and TAK1 by finding that the distance from amide $\mathrm{NH}$ at 3-position of thienopyrimidinone to the side chain of DFG Asp175 was $2.9 \AA$ and the distance from the $\mathrm{S}$ atom at 5-position of thienopyrimidinone to the side chain of gate keeper Met104 of $3.8 \AA$. Consequently, thienopyrimidinone of 1 had a tight interaction with Ala107, Glu77, and Asp175 by hydrogen bonding, and a weak hydrophobic interaction with Met104. Secondly, we explained the binding mode of 2 with TAK1 in the DFG-out conformation, in the same manner as we did for 1 (Fig. 2(b)). In contrast to 1, compound $\mathbf{2}$ changed the DFG motif structure and then induced a new hydrophobic pocket in TAK1 in the well-known DFG-out conformation; the urea group of $\mathbf{2}$ was located near the DFG loop, and the distance from the two $\mathrm{NH}$ groups in the urea group to the side chain carbonyl group of Glu77 was same, $2.9 \AA$ and the distance from the carbonyl group in the urea group to the backbone amide $\mathrm{NH}$ of Asp175 (DFG) was $3.0 \AA$, which meant that the compound interacted with TAK1 through three hydrogen bonds and subsequently the naphthalene ring was located in the new hydrophobic pocket, which indicated a hydrophobic interaction between $\mathbf{2}$ and TAK1. In the hinge region, the distance from $\mathrm{NH}$ group of the pyrrole ring of $\mathbf{2}$ to the carbonyl group of Ala107 was $3.1 \AA$, and the distance from the $\mathrm{N}$ atom in the pyridine ring of $\mathbf{2}$ to the backbone amide $\mathrm{NH}$ group of Ala107 was $2.9 \AA$. In other words, 2 has a tight interaction to TAK1 in the hinge region by two hydrogen bonds. As a result of this X-ray information on the complexes of TAK1 with both DFG-in and DFG-out inhibitors, we used type I inhibitor compound $\mathbf{1}$ as a scaffold and then superimposed compound $\mathbf{2}$ onto it to generate compound $\mathbf{3}$ as a new type II inhibitor (Fig. 2(c)). To avoid the repulsive coulomb against Phe176 in 

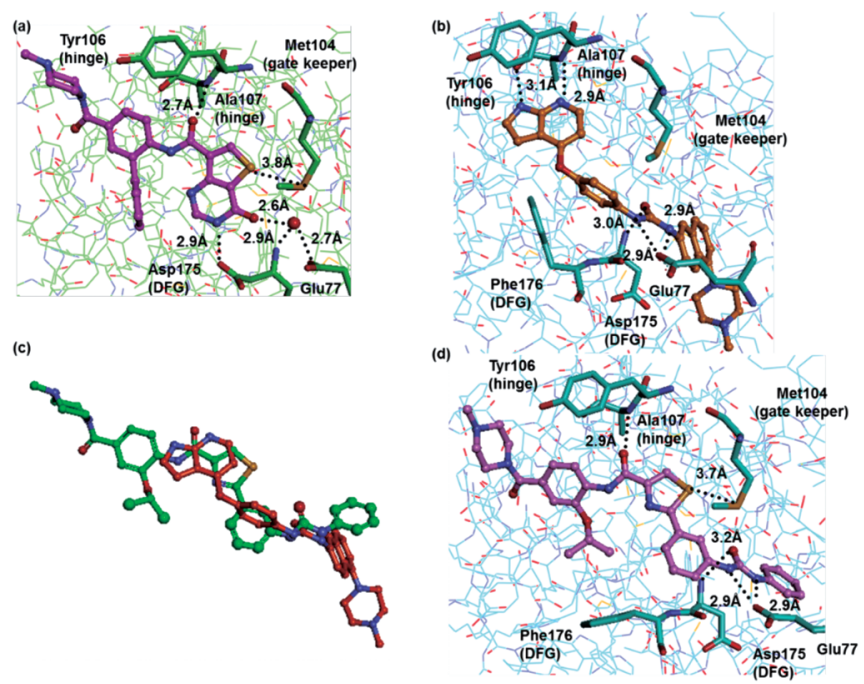

Fig. 2. (a) X-Ray Crystal Structure of $\mathbf{1}$ as a Type I Inhibitor in TAK1 (PDB Code: 5JGA); (b) X-Ray Crystal Structure of $\mathbf{2}$ as a Type II Inhibitor in TAK1 (PDB Code: 5GJD); (c) Our Designed Compound 3, Which Was Generated by Superimposing TAK1 Type I and Type II Inhibitors $(\mathbf{1}, \mathbf{2})$; (d) X-Ray Crystal Structure of $\mathbf{3}$ as a New Type II Inhibitor in TAK1 (PDB Code: 5GJF)

(a) $\mathbf{1}$ is shown as a ball and stick model colored by element type ( $\mathrm{C}$ in magenta, $\mathrm{O}$ in red, $\mathrm{N}$ in blue, $\mathrm{S}$ in yellow). Amino acid residues of TAK1 that interact with compound $\mathbf{1}$ are shown as stick models colored by element type with the same colors, except for $\mathrm{C}$ in light green. A representative crystallographic water is depicted as a red sphere. The key interactions are depicted as dotted lines. (b) 2 is shown as a ball and stick model colored by element type $(\mathrm{C}$ in orange, $\mathrm{O}$ in red, $\mathrm{N}$ in blue, $\mathrm{S}$ in yellow). Amino acid residues of TAK1 that interact with 2 are shown as stick models and shown in the same colors except for $\mathrm{C}$, which is cyan in TAK1. The key hydrogen bonding interactions are depicted as dotted lines. (c) 2 is shown as a ball and stick model colored by element type ( $\mathrm{C}$ orange, $\mathrm{O}$ in red, $\mathrm{N}$ in blue, $\mathrm{S}$ in yellow) and $\mathbf{3}$ is shown in the same colors except for C, which is light green. (d) 3 is shown as a ball and stick model colored by element type ( $\mathrm{C}$ in magenta, $\mathrm{O}$ in red, $\mathrm{N}$ in blue, $\mathrm{S}$ in yellow). Amino acid residues of TAK1 that interact with $\mathbf{3}$ are shown as stick models colored by element type with the same colors except for C, which is cyan in TAK1. The key hydrogen bonding interactions are depicted as dotted lines.

the TAK1 DFG-out conformation, we converted thienopyrimidinone ring of 1 into phenyl thiazole, which maintained the planarity of compound 3 by having an intramolecular hydrogen bond between the $\mathrm{N}$ atom of thiazole and amide $\mathrm{NH}$ located near the hinge position, instead of having the $\mathrm{N}$ atom at 1-position of compound 1's thienopyrimidinone ring. Next we installed the urea group at $m$-position of phenyl thiazole (overlapping with the corresponding urea group of compound 2) and the benzene ring at the terminal of urea (relatively matching the corresponding naphthalene ring of 2) in the expectation of gaining a hydrophobic interaction in the newly induced hydrophobic pocket in the TAK1 DFG-out conformation.

The TAK1 inhibitory activity of $\mathbf{3}$ was not sufficiently satisfactory $\left(\mathrm{TAK} 1 \mathrm{IC}_{50}=260 \mathrm{~nm}\right.$ ), but X-ray structure analysis confirmed compound $\mathbf{3}$ as a new chemical class bound to TAK1 in the DFG-out conformation. This X-ray information revealed that 3 changed the DFG motif structure and then induced a new hydrophobic pocket in TAK1 like compound 2, as we had expected (Fig. 2(d)). Furthermore, the urea group of $\mathbf{3}$ was located near the DFG loop and the distance from the two $\mathrm{NH}$ groups in the urea to the side chain carbonyl group of Glu77 was same, $2.9 \AA$ and the distance from the carbonyl group in the urea to the backbone amide NH group of Asp175 (DFG) was $3.2 \AA$, which provided interactions with TAK1 through three hydrogen bonds and the benzene ring was lo- (a)
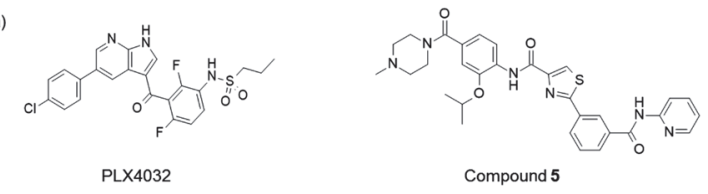

(b)

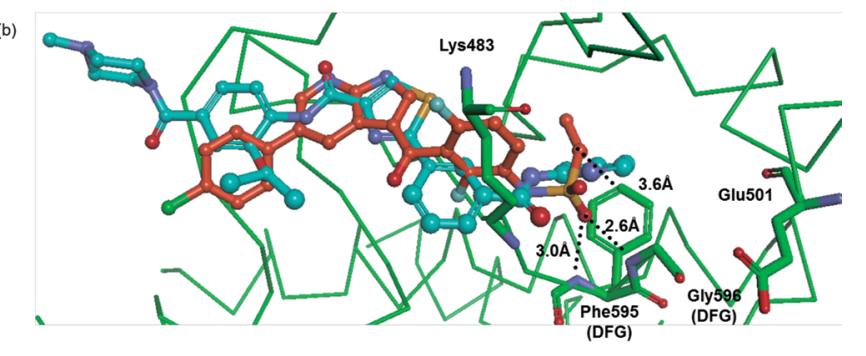

(c)

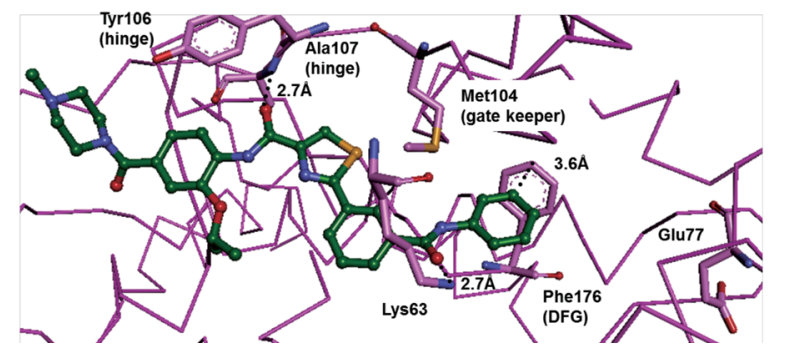

Fig. 3. (a) Structure of PLX4032 and Our Designed Compound 5; (b) Superimposition of Our Designed Compound 5 onto PLX4032 in b-Raf (PDB Code: 3OG7); (c) X-Ray Crystal Structure of $\mathbf{4}$ as a New c-HelixOut Inhibitor in Complex with TAK1 (PDB Code: 5GJG)

$(a, b) 5$ was generated by superimposition of the TAK1 type I inhibitor 1 (PDB code: 5JGA) and a b-Raf c-helix-out inhibitor, PLX4032. PLX4032 is shown as a ball and stick model colored by element type ( $\mathrm{C}$ in orange, $\mathrm{O}$ in red, $\mathrm{N}$ in blue, $\mathrm{S}$ in yellow, $\mathrm{F}$ in light blue, $\mathrm{Cl}$ in light green) and $\mathbf{5}$ is shown in the same colors except for $\mathrm{C}$, which is cyan. Amino acid residues of b-Raf that interact with PLX4032 are shown as stick models colored by element type with the same colors except for C, which is light green in b-Raf. The key hydrogen bonding interactions are depicted as dotted lines. (c) $\mathbf{4}$ is shown as a ball and stick model colored by element type (C in dark green, $\mathrm{O}$ in red, $\mathrm{N}$ in blue, $\mathrm{S}$ in yellow). Amino acid residues of TAK1 that interact with $\mathbf{4}$ are shown as stick models colored by element type with the same colors except for $\mathrm{C}$, which is magenta in TAK1. The key hydrogen bonding interactions are depicted as dotted lines.

cated in a new hydrophobic pocket. As we expected, the binding modes of $\mathbf{2}$ and $\mathbf{3}$ were very similar and both compounds induced a TAK1 DFG-out conformation. Next, in the hinge region, the distance from the carbonyl group adjacent thiazole to the backbone amide $\mathrm{NH}$ of Ala107 was $2.9 \AA$, which created a hydrogen bond interaction with TAK1 in this region. Finally, near the gatekeeper, the distance from the $\mathrm{S}$ atom of thiazole to the side chain of Met104 was $3.7 \AA$, which indicated a weak hydrophobic interaction with Met104.

In the second conversion process, from a TAK1 type I inhibitor into a c-helix-out inhibitor by SBDD, we used modeling to compare results with a known b-Raf c-helix-out inhibitor. As described above, we argued that because TAK1 and b-Raf were located very closely in Sugen kinase tree, these kinases were very similar. At the beginning of this study, the X-ray crystal structure of the complexes between several ligands and $\mathrm{b}$-Raf were solved by several groups and the c-helix-out conformation that b-Raf possessed had been elucidated, ${ }^{23,27)}$ although a c-helix-out conformation for TAK1 had not yet been reported. We speculated that TAK1 also had a c-helix-out conformation like b-Raf; therefore, new chelix-out TAK1 inhibitors were designed by SBDD utilizing a known b-Raf c-helix-out inhibitor, represented by PLX4032 (PDB code: 3OG7) ${ }^{23)}$ Our designed compounds 4, 5, and $\mathbf{6}$ 
were based on compound $\mathbf{1}$ as a scaffold, like the conversion from type I inhibitor to type II inhibitor. To design compound 5, we superimposed our designed compound $\mathbf{5}$ onto PLX4032 in b-Raf with the c-helix-out conformation (Fig. 3(b)). At first, we described the interactions between PLX4032 and b-Raf near the DFG loop. The X-ray information of the complex between PLX4032 and b-Raf showed that the binding mode of PLX4032 was c-helix out; the propyl group of PLX4032 was shifted c-helix loop and disrupted a salt bridge between Lys483 and Glu501 to induce a new hydrophobic pocket and the distance from the propyl group to the side chain of Phe595 in b-Raf was $3.6 \AA$, which provided hydrophobic interaction with $\mathrm{b}$-Raf at this pocket. In addition, the X-ray information revealed that the distances from $\mathrm{O}$ atom of the sulfonamide group of PLX4032 to the backbone NH of both Phe595 and Gly596 were 3.0 and $2.6 \AA$, which created two hydrogen bonding with both Phe595 and Gly596 in b-Raf. On the basis of these findings, we designed compound 5, which converted thienopyrimidinone ring of $\mathbf{1}$ into phenyl thiazole, as we had in compound $\mathbf{3}$ and then installed the pyridine ring at $\mathrm{m}$ position of phenyl thiazole utilizing amide group, which was expected to interact with the side chain of Phe176 (DFG) in TAK1 corresponding Phe596 in b-Raf by $\pi-\pi$ interaction and we assumed that this pyridine amide would mimic $\mathrm{O}$ atom of the sulfonamide group of PLX4032; $\mathrm{N}$ atom of the pyridine ring was expected to interact with backbone $\mathrm{NH}$ of Gly177 in TAK1 corresponding Gly596 in b-Raf by hydrogen bonding and the carbonyl group of this pyridine amide was expected to interact with backbone NH of Phe176 corresponding Phe595 in b-Raf. Additionally, we assumed that the distance from carbonyl group of this pyridine amide to Lys63 in TAK1 corresponding Lys483 in b-Raf was more closer than the distance from $\mathrm{O}$ atom of the sulfonamide group of PLX4032 to Lys483 in b-Raf, so our designed compound $\mathbf{5}$ would interact with the side chain amino group of Lys63 in TAK1 by a hydrogen bonding.

At first, we tried to obtain the co-crystal of compound $\mathbf{5}$ and TAK1 to confirm the binding mode of $\mathbf{5}$ in TAK1, but unfortunately we were not able to acquire it. While, the X-ray structure of TAK1 and compound $\mathbf{4}$ complex was solved, therefore the confirmation of the binding mode between our designed c-helix-out inhibitor and TAK1 was conducted by utilizing this information. As we expected, X-ray structure analysis confirmed compound 4 (TAK1 $\mathrm{IC}_{50}=610 \mathrm{nM}$ ) as a new chemical class bound to TAK1 in the c-helix-out conformation and reveal that $\mathbf{4}$ was located in the ATP binding site with a DFG-in conformation and had shifted the c-helix loop to induce a new hydrophobic pocket in TAK1 (especially, a salt bridge between Lys63 and Glu77 was disrupted), like PLX4032 had done in b-Raf with a c-helix-out conformation, and finally that the benzene ring of $\mathbf{4}$ was fitted into this new lipophilic pocket in TAK1 (Fig. 3(c)). This is the first report of a TAK1 c-helix-out inhibitor. Furthermore, we revealed the binding mode of $\mathbf{4}$ in TAK1 c-helix-out conformation; the distance from the carbonyl group located near the DFG loop of 4 to the side chain amino group of Lys63 was $2.7 \AA$, which provided interaction with TAK1 through a hydrogen bond and the distance from the benzene ring of $\mathbf{4}$ to the side chain of Phe176 (DFG) was 3.6 , which meant hydrophobic interaction with Phe176 in TAK1 by $\pi-\pi$ interaction as we expected, secondary in the hinge region, the distance from the carbonyl group adjacent thiazole to the backbone amide NH of Ala107 was $2.7 \AA$, which created a hydrogen bond interaction with TAK1 like compounds $\mathbf{1}$ and $\mathbf{3}$, finally, near the gatekeeper, the distance from the $\mathrm{S}$ atom of thiazole to the side chain of Met104 was $4.0 \AA$, which indicated a weak hydrophobic interaction with Met104. Although the X-ray crystal structure of compounds $\mathbf{5}$ and $\mathbf{6}$ in the complexes with TAK1 was not able to be solved, we supposed that both compounds also bound to TAK1 with c-helix-out conformation (TAK1 $\mathrm{IC}_{50}=900,110 \mathrm{~nm}$, respectively). When the inhibitory activity of $\mathbf{4}, \mathbf{5}$, and $\mathbf{6}$ on TAK1 was compared, $\mathbf{6}$ was the most potent TAK1 inhibitor, probably because the pyridine ring $\mathrm{N}$ atom of 6 interacted with the backbone amide NH group of Gly177 (this amino acid residue was not visible clearly in the X-ray information of the complex between 4 and TAK1) by hydrogen bonding like PLX4032, whereas 4 had no $\mathrm{N}$ atom in this area and thus lacked a hydrogen bond with TAK1. Moreover, although 5 possessed $\mathrm{N}$ atom like $\mathbf{6}$, this $\mathrm{N}$ atom formed an intramolecular hydrogen bond with the amide $\mathrm{NH}$ group, so this $\mathrm{N}$ atom did not work well as an acceptor for TAK1. As a result, we augured that $\mathbf{6}$ was a relatively potent TAK1 inhibitor compared with both $\mathbf{4}$ or $\mathbf{5}$.

\section{Conclusion}

In summary, we have achieved conversions from a type I inhibitor into a type II inhibitor (compound 3) or into c-helixout inhibitors (compounds 4, 5, and 6) by structure-based drug design (SBDD) and have obtained inhibitors in those chemical classes, which marks the first reported discovery of a c-helix-out inhibitor against TAK1. We have already reported our novel TAK1 type I inhibitors and X-ray information on those compounds in complex with TAK1 in the DFGin conformation. Additionally, we had previously obtained a type II TAK1 binder, the biaryl urea compound 2 (TAK1 $K_{\mathrm{d}}=12 \mathrm{~nm}$ ) with multi-kinase inhibitory activity. Fortunately, we were able to gain a co-crystal of 2 in complex with TAK1 in the DFG-out conformation; therefore, we superimposed the $\mathrm{X}$-ray structures of $\mathbf{1}$ and $\mathbf{2}$ to design compound $\mathbf{3}$ by modeling as a new chemical class type II inhibitor. As expected, $\mathrm{X}$-ray structure analysis confirmed that compound $\mathbf{3}$ bound to TAK1 with a DFG-out conformation and also revealed that 3 changed the DFG motif structure and then induced a new hydrophobic pocket in TAK1, like compound 2 . On the other hand, to convert from a TAK1 type I inhibitor into a c-helixout inhibitor by SBDD, we exploited modeling from comparison with a known b-Raf c-helix-out inhibitor, PLX4032, which was chosen because TAK1 and b-Raf are located closely in the Sugen kinase tree, so we considered that TAK1 would also form c-helix-out conformation like b-Raf dose. Our designed compounds $\mathbf{4}, \mathbf{5}$, and $\mathbf{6}$ were based on compound $\mathbf{1}$ as a scaffold like the conversion from type I inhibitor to type II inhibitor. As expected, X-ray structure analysis confirmed compound 4 as a new chemical class bound to TAK1 with a c-helix-out conformation and revealed that $\mathbf{4}$ was located in the ATP binding-site in a DFG-in conformation and had shifted the c-helix loop to induce a new hydrophobic pocket in TAK1, like PLX4032 in b-Raf, with a c-helix-out conformation. When the inhibitory activity of $\mathbf{4 , 5}$, and $\mathbf{6}$ against TAK1 was compared, $\mathbf{6}$ was the most potent TAK1 inhibitor, which indicated that the pyridine ring $\mathrm{N}$ atom of $\mathbf{6}$ interacted with TAK1 by hydrogen bonding. 
Because this was a preliminary study, the TAK1 inhibitory activity of our designed compounds $(\mathbf{3}, \mathbf{4}, \mathbf{5}$, and $\mathbf{6})$ was relatively weak; therefore, further optimization of these series to improve TAK1 inhibitory activity and physicochemical property is ongoing. After that, we would like to compare the kinase selectivity profile of these different TAK1 inhibitors and report this result. However, we consider these converting methods could be adapted to other kinases and effective strategy for kinase inhibitor development to prepare simultaneously these different types.

\section{Experimental}

Chemistry: General Purchased reagents and solvents were used without further purification unless otherwise noted. ${ }^{1} \mathrm{H}$ and ${ }^{13} \mathrm{C}$ spectra were recorded on VARIAN $400-\mathrm{MR}$ or Bruker ASCEND400 and chemical shifts are expressed in parts per million (ppm) from tetramethylsilane (TMS) as an internal standard. The spectrum patterns are described as follows: $\mathrm{s}=$ singlet, $\mathrm{d}=$ doublet, $\mathrm{t}=$ triplet, $\mathrm{q}=$ quartet, $\mathrm{br}=$ broad, $\mathrm{m}=$ multiplet. LC-MS were measured by a Waters ACQUITY SQD electrospray ionization (ESI) system. High resolution (HR)-MS were measured with a Waters I-Class/Xevo G2S TOF using an ESI source coupled to a Waters HPLC system operating in reversed phase without column. NH-silica gel chromatography and preparative TLC were conducted with FUJI SILYSIA NH-DM1020 and Merck silica gel $60 \mathrm{PF}_{254}$, respectively. Reversed column chromatography was conducted with an octadecyl silica (ODS) column, Wakosil ${ }^{\circledR} 25 \mathrm{C} 18$.

2-Bromo-N-(2-isopropoxy-4-(4-methylpiperazine-1carbonyl)phenyl)thiazole-4-carboxamide (8)

To a solution of commercially available 2-bromothiazole4-carboxylic acid $(557 \mathrm{mg}, 2.68 \mathrm{mmol})$ in acetonitrile $(15.0 \mathrm{~mL})$ was added HATU $(1.53 \mathrm{~g}, 4.02 \mathrm{mmol}), \mathrm{N}, \mathrm{N}$-diisopropylethylamine (DIPEA) $(936 \mu \mathrm{L}, 5.36 \mathrm{mmol})$ and (4-amino-3-isopropoxyphenyl)(4-methylpiperazin-1-yl)methanone 7 (743 $\mathrm{mg}$, $2.68 \mathrm{mmol}$ ) and stirred at room temperature for $3 \mathrm{~h}$. After evaporation to remove acetonitrile, the obtained residue was purified by column chromatography utilizing $\mathrm{NH}$ silica gel (hexane-ethyl acetate) to afford $8(1.04 \mathrm{~g}, 83 \%)$ as a light yellow oil. ${ }^{1} \mathrm{H}-\mathrm{NMR}\left(400 \mathrm{MHz}, \mathrm{DMSO}-d_{6}\right) \delta: 9.78(1 \mathrm{H}, \mathrm{s})$, $8.50(1 \mathrm{H}, \mathrm{s}), 8.36(1 \mathrm{H}, \mathrm{d}, J=8.1 \mathrm{~Hz}), 7.14(1 \mathrm{H}, \mathrm{s}), 7.02(1 \mathrm{H}, \mathrm{d}$, $J=8.1 \mathrm{~Hz}), 4.78-4.72(1 \mathrm{H}, \mathrm{m}), 3.48$ (4H, brs), 2.32 (4H, brs), $2.20(3 \mathrm{H}, \mathrm{s}), 1.36(6 \mathrm{H}, \mathrm{d}, J=5.9 \mathrm{~Hz}) .{ }^{13} \mathrm{C}-\mathrm{NMR}(100 \mathrm{MHz}$, DMSO- $\left.d_{6}\right) \delta: 168.4,156.7,148.8,145.9,137.2,131.7,130.0$, 128.9, 119.8, 118.5, 112.8, 71.8, 54.4, 45.6, 21.8. HR-MS (ESItime-of-flight (TOF)) $m / z$ : $[\mathrm{M}+\mathrm{H}]^{+}$Calcd for $\mathrm{C}_{19} \mathrm{H}_{24} \mathrm{BrN}_{4} \mathrm{O}_{3} \mathrm{~S}$ 467.0753. Found 467.0760.

2-(3-Aminophenyl)- $N$-(2-isopropoxy-4-(4-methylpiperazine1-carbonyl)phenyl)thiazole-4-carboxamide (9)

A solution of $\mathbf{8}(110 \mathrm{mg}, 0.235 \mathrm{mmol}), m$-aminophenylboronic acid $(64.5 \mathrm{mg}, 0.471 \mathrm{mmol}), \mathrm{K}_{3} \mathrm{PO}_{4}(175 \mathrm{mg}, 0.824 \mathrm{mmol})$, $\mathrm{Pd}(\mathrm{OAc})_{2}(5.28 \mathrm{mg}, 23.5 \mu \mathrm{mol})$ and $\mathrm{S}-\mathrm{Phos}(19.3 \mathrm{mg}, 47.0 \mu \mathrm{mol})$ in toluene $(2.50 \mathrm{~mL})$ was stirred at $100^{\circ} \mathrm{C}$ for $8 \mathrm{~h}$ under nitrogen atmosphere. After the filtration with Celite ${ }^{\circledR}$, the obtained filtrate was evaporated and purified by column chromatography utilizing NH silica gel (hexane-ethyl acetate) to afford a semi pure product. After that, reversed column chromatography (ODS, $10 \mathrm{mM} \mathrm{NH}_{4} \mathrm{OAc} \mathrm{H}_{2} \mathrm{O}$-methanol) was conducted to give $9(57.0 \mathrm{mg}, 51 \%)$ as a white amorphous. ${ }^{1} \mathrm{H}-\mathrm{NMR}\left(400 \mathrm{MHz}, \mathrm{DMSO}-d_{6}\right) \delta: 10.16(1 \mathrm{H}, \mathrm{s}), 8.48(1 \mathrm{H}, \mathrm{s})$, $8.45(1 \mathrm{H}, \mathrm{d}, J=8.6 \mathrm{~Hz}), 7.20-7.16(4 \mathrm{H}, \mathrm{m}), 7.04-7.03(1 \mathrm{H}, \mathrm{m})$,
6.75-6.74 (1H, m), $5.40(2 \mathrm{H}$, brs $), 4.80-4.79(1 \mathrm{H}, \mathrm{m}), 3.51$ (4H, brs), $2.33(4 \mathrm{H}$, br s), $2.20(3 \mathrm{H}, \mathrm{s}), 1.42(6 \mathrm{H}, \mathrm{d}, J=5.9 \mathrm{~Hz})$. ${ }^{13} \mathrm{C}-\mathrm{NMR}\left(100 \mathrm{MHz}, \mathrm{DMSO}-d_{6}\right) \delta: 168.7,168.5,158.0,149.6$, $149.5,145.7,132.6,131.3,129.8,129.2,124.9,119.8,118.0$, 116.6, 113.3, 112.6, 111.3, 71.7, 54.4, 45.6, 21.8. HR-MS (ESITOF) $m / z:[\mathrm{M}+\mathrm{H}]^{+}$Calcd for $\mathrm{C}_{25} \mathrm{H}_{30} \mathrm{~N}_{5} \mathrm{O}_{3} \mathrm{~S}$ 480.2069. Found 480.2069 .

$N$-(2-Isopropoxy-4-(4-methylpiperazine-1-carbonyl)phenyl)2-(3-(3-phenylureido)phenyl)thiazole-4-carboxamide (3)

A solution of $9(20.0 \mathrm{mg}, 0.0417 \mathrm{mmol})$ and phenyl isocyanate $(22.6 \mu \mathrm{L}, 0.209 \mathrm{mmol})$ in THF $(200 \mu \mathrm{L})$ was stirred at $60^{\circ} \mathrm{C}$ for $30 \mathrm{~min}$. The reaction mixture was evaporated and the obtained residue was purified by reversed column chromatography $\left(0.1 \% \mathrm{HCOOH} \mathrm{H}_{2} \mathrm{O}-0.1 \% \mathrm{HCOOH}\right.$ acetonitrile) to afford $3(19.0 \mathrm{mg}, 76 \%)$ as a light yellow amorphous. ${ }^{1} \mathrm{H}-\mathrm{NMR}$ $\left(400 \mathrm{MHz}, \mathrm{DMSO}-d_{6}\right) \delta: 10.11(1 \mathrm{H}, \mathrm{s}), 8.94(1 \mathrm{H}, \mathrm{s}), 8.77(1 \mathrm{H}$, s), $8.55(1 \mathrm{H}, \mathrm{s}), 8.47-8.46(2 \mathrm{H}, \mathrm{m}), 7.65(1 \mathrm{H}, \mathrm{d}, J=8.1 \mathrm{~Hz})$, $7.50-7.47(3 \mathrm{H}, \mathrm{m}), 7.38(1 \mathrm{H}, \mathrm{d}, J=8.6 \mathrm{~Hz}), 7.31-7.29(2 \mathrm{H}, \mathrm{m})$, $7.14(1 \mathrm{H}, \mathrm{s}), 7.03-6.98(2 \mathrm{H}, \mathrm{m}), 4.79-4.78(1 \mathrm{H}, \mathrm{m}), 3.50(4 \mathrm{H}$, brs), 2.33 (4H, brs), $2.20(3 \mathrm{H}, \mathrm{s}), 1.40(6 \mathrm{H}, \mathrm{d}, J=5.9 \mathrm{~Hz})$. ${ }^{13} \mathrm{C}-\mathrm{NMR}\left(100 \mathrm{MHz}, \mathrm{DMSO}-d_{6}\right) \delta: 168.5,168.0,157.9,152.5$, $149.7,145.7,140.7,139.5,132.6,131.4,129.8,129.1,128.7$, $125.6,122.0,120.9,119.7,118.3,118.1,115.9,112.4,71.7$, 54.5, 45.6, 21.7. HR-MS (ESI-TOF) $\mathrm{m} / \mathrm{z}:[\mathrm{M}+\mathrm{H}]^{+}$Calcd for $\mathrm{C}_{32} \mathrm{H}_{35} \mathrm{~N}_{6} \mathrm{O}_{4} \mathrm{~S}$ 599.2441. Found 599.2455.

3-(4-((2-Isopropoxy-4-(4-methylpiperazine-1-carbonyl)phenyl)carbamoyl)thiazol-2-yl)benzoic Acid (10)

A solution of 8 ( $250 \mathrm{mg}, 0.535 \mathrm{mmol}), m$-(methoxycarbonyl)phenylboronic acid (193 mg, $1.07 \mathrm{mmol}), \mathrm{K}_{3} \mathrm{PO}_{4} \quad(397 \mathrm{mg}$, $1.87 \mathrm{mmol}), \quad \mathrm{Pd}(\mathrm{OAc})_{2} \quad(12.0 \mathrm{mg}, \quad 53.5 \mu \mathrm{mol})$, and S-Phos $(43.9 \mathrm{mg}, 10.7 \mu \mathrm{mol})$ in toluene $(5.40 \mathrm{~mL})$ was stirred at $100^{\circ} \mathrm{C}$ for $4 \mathrm{~h}$ under nitrogen atmosphere. After the reaction mixture was filtered and evaporated, the obtained crude residue was purified by column chromatography utilizing $\mathrm{NH}$ silica gel (hexane-ethyl acetate) to afford methyl 3-(4-((2-isopropoxy-4(4-methylpiperazine-1-carbonyl)phenyl)carbamoyl)thiazol-2yl)benzoate as a light yellow amorphous (237 $\mathrm{mg}, 85 \%)$. ${ }^{1} \mathrm{H}-\mathrm{NMR}\left(400 \mathrm{MHz}, \mathrm{DMSO}-d_{6}\right) \delta: 10.14(1 \mathrm{H}, \mathrm{s}), 8.64(1 \mathrm{H}, \mathrm{s})$, $8.62(1 \mathrm{H}, \mathrm{s}), 8.47(1 \mathrm{H}, \mathrm{d}, J=8.1 \mathrm{~Hz}), 8.28(1 \mathrm{H}, \mathrm{d}, J=7.5 \mathrm{~Hz})$, $8.14(1 \mathrm{H}, \mathrm{d}, J=7.5 \mathrm{~Hz}), 7.74(1 \mathrm{H}, \mathrm{dd}, J=7.7,7.7 \mathrm{~Hz}), 7.17(1 \mathrm{H}$, s), $7.04(1 \mathrm{H}, \mathrm{d}, J=7.0 \mathrm{~Hz}), 4.84-4.82(1 \mathrm{H}, \mathrm{m}), 3.93(3 \mathrm{H}, \mathrm{s}), 3.49$ (4H, brs), 2.33 (4H, brs), $2.20(3 \mathrm{H}, \mathrm{s}), 1.45(6 \mathrm{H}, \mathrm{d}, J=5.9 \mathrm{~Hz})$. ${ }^{13} \mathrm{C}-\mathrm{NMR}\left(100 \mathrm{MHz}, \mathrm{DMSO}-d_{6}\right) \delta: 168.5,166.5,165.5,157.7$, $149.9,146.6,145.7,132.4,131.4,131.2,130.8,130.1,129.1$, 126.2, 125.9, 119.8, 118.0, 112.5, 71.7, 54.4, 52.5, 45.6, 21.8. HR-MS (ESI-TOF) m/z: $[\mathrm{M}-\mathrm{H}]^{+}$Calcd for $\mathrm{C}_{27} \mathrm{H}_{31} \mathrm{~N}_{4} \mathrm{O}_{5} \mathrm{~S}$ 523.2015. Found 523.2029.

To a solution of methyl 3-(4-((2-isopropoxy-4-(4methylpiperazine-1-carbonyl)phenyl)carbamoyl)thiazol-2-yl)benzoate $(100 \mathrm{mg}, 0.191 \mathrm{mmol})$ in THF $(1.00 \mathrm{~mL})$ was added $2 \mathrm{~N} \mathrm{LiOH}$ aq. $(480 \mu \mathrm{L}, 0.960 \mathrm{mmol})$ and stirred at room temperature for $7 \mathrm{~h}$. After the addition of $\mathrm{HCOOH}(73.0 \mu \mathrm{L}$, $1.91 \mathrm{mmol}$ ) and evaporation, the obtained residue was purified by reversed column chromatography (ODS, 0.1\% $\mathrm{HCOOH}$ $\mathrm{H}_{2} \mathrm{O}-0.1 \% \mathrm{HCOOH}$ acetonitrile) to afford $\mathbf{1 0}$ (98.0 mg, quant.) as a white solid. ${ }^{1} \mathrm{H}-\mathrm{NMR}\left(400 \mathrm{MHz}, \mathrm{DMSO}-d_{6}\right) \delta$ : 10.17 $(1 \mathrm{H}, \mathrm{s}), 8.66(1 \mathrm{H}, \mathrm{s}), 8.60(1 \mathrm{H}, \mathrm{s}), 8.48(1 \mathrm{H}, \mathrm{d}, J=8.1 \mathrm{~Hz}), 8.24$ $(1 \mathrm{H}, \mathrm{d}, J=7.5 \mathrm{~Hz}), 8.11(1 \mathrm{H}, \mathrm{d}, J=7.5 \mathrm{~Hz}), 7.71(1 \mathrm{H}, \mathrm{dd}, J=7.7$, $7.7 \mathrm{~Hz}), 7.16(1 \mathrm{H}, \mathrm{s}), 7.04(1 \mathrm{H}, \mathrm{d}, J=8.1 \mathrm{~Hz}), 4.82-4.81(1 \mathrm{H}$, m), 3.50 (4H, brs), 2.35 (4H, brs), $2.22(3 \mathrm{H}, \mathrm{s}), 1.43(6 \mathrm{H}, \mathrm{d}$, $J=5.9 \mathrm{~Hz}) .{ }^{13} \mathrm{C}-\mathrm{NMR}\left(100 \mathrm{MHz}, \mathrm{DMSO}-d_{6}\right) \delta: 168.5,166.7$, 
$166.6,157.8,149.8,145.7,132.4,132.2,131.5,131.3,130.5$, $129.9,129.2,126.4,126.0,119.8,117.9,112.5,71.7,54.4,45.5$, 21.9. HR-MS (ESI-TOF) $m / z$ : $[\mathrm{M}-\mathrm{H}]^{+}$Calcd for $\mathrm{C}_{26} \mathrm{H}_{29} \mathrm{~N}_{4} \mathrm{O}_{5} \mathrm{~S}$ 509.1859. Found 509.1863.

$N$-(2-Isopropoxy-4-(4-methylpiperazine-1-carbonyl)phenyl)2-(3-(phenylcarbamoyl)phenyl)thiazole-4-carboxamide (4)

To a solution of $\mathbf{1 0}(20.0 \mathrm{mg}, 39.3 \mu \mathrm{mol})$ and aniline $(3.7 \mathrm{mg}$, $39.3 \mu \mathrm{mol})$ in acetonitrile $(200 \mu \mathrm{L})$ was added HATU $(16.4 \mathrm{mg}$, $43.2 \mu \mathrm{mol})$ and DIPEA $(10.3 \mu \mathrm{L}, 59.0 \mu \mathrm{mol})$ and stirred at $80^{\circ} \mathrm{C}$. After the starting material consumption had been confirmed by LC-MS, the reaction mixture was concentrated to give a crude residue. The crude residue was purified by preparative TLC (dichloromethane (DCM)-methanol) to afford a semi-pure solid. The solid was washed with $\mathrm{H}_{2} \mathrm{O}$ to give 4 (13.6 mg, 59\%) as a white solid. ${ }^{1} \mathrm{H}-\mathrm{NMR}(400 \mathrm{MHz}, \mathrm{DMSO}-$ $\left.d_{6}\right) \delta: 10.51(1 \mathrm{H}, \mathrm{s}), 10.21(1 \mathrm{H}, \mathrm{s}), 8.63(1 \mathrm{H}, \mathrm{s}), 8.61-8.58(1 \mathrm{H}$, $\mathrm{m}), 8.47(1 \mathrm{H}, \mathrm{d}, J=8.2 \mathrm{~Hz}), 8.24-8.22(1 \mathrm{H}, \mathrm{m}), 8.11-8.08(1 \mathrm{H}$, $\mathrm{m}), 7.81-7.72(3 \mathrm{H}, \mathrm{m}), 7.39-7.37(2 \mathrm{H}, \mathrm{m}), 7.14-7.12(2 \mathrm{H}, \mathrm{m})$, $7.03(1 \mathrm{H}, \mathrm{d}, J=8.2 \mathrm{~Hz}), 4.77-4.75(1 \mathrm{H}, \mathrm{m}), 3.50$ (4H, brs), 2.33 (4H, brs), $2.21(3 \mathrm{H}, \mathrm{s}), 1.34(6 \mathrm{H}, \mathrm{d}, J=5.9 \mathrm{~Hz}) .{ }^{13} \mathrm{C}-\mathrm{NMR}$ $\left(100 \mathrm{MHz}, \mathrm{DMSO}-d_{6}\right) \delta$ : $168.5,166.9,164.9,157.8,149.8$, $145.7,139.0,136.5,132.1,131.3,130.1,129.6,129.2,129.1$, $128.6,126.1,125.1,123.8,120.3,119.8,118.0,112.4,71.5$, 54.3, 45.4, 21.7. HR-MS (ESI-TOF) $\mathrm{m} / \mathrm{z}:[\mathrm{M}+\mathrm{H}]^{+}$Calcd for $\mathrm{C}_{32} \mathrm{H}_{34} \mathrm{~N}_{5} \mathrm{O}_{4} \mathrm{~S}$ 584.2332. Found 584.2351.

Both compounds 5 and $\mathbf{6}$ were synthesized by a similar procedure to 4 .

$N$-(2-Isopropoxy-4-(4-methylpiperazine-1-carbonyl)phenyl)2-(3-(pyridin-2-ylcarbamoyl)phenyl)thiazol-4-carboxamide (5)

The yield was $57 \%$. Light yellow solid. ${ }^{1} \mathrm{H}-\mathrm{NMR}$ (DMSO$\left.d_{6}\right) \delta: 11.13(1 \mathrm{H}, \mathrm{s}), 10.21(1 \mathrm{H}, \mathrm{s}), 8.66(1 \mathrm{H}, \mathrm{s}), 8.61(1 \mathrm{H}, \mathrm{s}), 8.47$ $(1 \mathrm{H}, \mathrm{d}, J=8.1 \mathrm{~Hz}), 8.42(1 \mathrm{H}, \mathrm{d}, J=3.8 \mathrm{~Hz}), 8.25-8.23(2 \mathrm{H}, \mathrm{m})$, $8.16(1 \mathrm{H}, \mathrm{d}, J=8.1 \mathrm{~Hz}), 7.89-7.87(1 \mathrm{H}, \mathrm{m}), 7.72(1 \mathrm{H}, \mathrm{dd}, J=7.7$, $7.7 \mathrm{~Hz}), 7.21-7.19(1 \mathrm{H}, \mathrm{m}), 7.14(1 \mathrm{H}, \mathrm{s}), 7.04(1 \mathrm{H}, \mathrm{d}, J=8.1 \mathrm{~Hz})$, 4.80-4.74 (1H, m), 3.51 (4H, brs), $2.33(4 \mathrm{H}, \mathrm{brs}), 2.20(3 \mathrm{H}$, s), $1.36(6 \mathrm{H}, \mathrm{d}, J=6.4 \mathrm{~Hz}) .{ }^{13} \mathrm{C}-\mathrm{NMR}\left(100 \mathrm{MHz}, \mathrm{DMSO}-d_{6}\right) \delta$ : 168.5 166.9, 165.4, 157.8, 152.1, 149.7, 147.9, 145.7, 143.3, 138.1, $135.5,132.0,131.4,130.4,129.5,129.3,129.1,126.1,125.9$, $119.9,119.7,118.0,114.6,112.4,71.6,54.4,45.6$, 21.7. HR-MS (ESI-TOF) $m / z:[\mathrm{M}+\mathrm{H}]^{+}$Calcd for $\mathrm{C}_{31} \mathrm{H}_{33} \mathrm{~N}_{6} \mathrm{O}_{4} \mathrm{~S}$ 585.2284. Found 585.2284.

$N$-(2-Isopropoxy-4-(4-methylpiperazine-1-carbonyl)phenyl)2-(3-(pyridin-3-ylcarbamoyl)phenyl)thiazole-4-carboxamide (6)

The yield was $81 \%$. Light brown solid. ${ }^{1} \mathrm{H}-\mathrm{NMR}(400 \mathrm{MHz}$, DMSO-d $d_{6} \delta$ : $10.73(1 \mathrm{H}, \mathrm{s}), 10.20(1 \mathrm{H}, \mathrm{s}), 8.97(1 \mathrm{H}, \mathrm{s}), 8.63$ $(2 \mathrm{H}, \mathrm{s}), 8.47(1 \mathrm{H}, \mathrm{d}, J=8.1 \mathrm{~Hz}), 8.35(1 \mathrm{H}, \mathrm{d}, J=3.8 \mathrm{~Hz})$, $8.26-8.22(2 \mathrm{H}, \mathrm{m}), 8.12(1 \mathrm{H}, \mathrm{d}, J=8.1 \mathrm{~Hz}), 7.77(1 \mathrm{H}, \mathrm{dd}, J=7.7$, $7.7 \mathrm{~Hz}), 7.44(1 \mathrm{H}, \mathrm{dd}, J=8.3,4.6 \mathrm{~Hz}), 7.13(1 \mathrm{H}, \mathrm{s}), 7.03(1 \mathrm{H}, \mathrm{d}$, $J=8.1 \mathrm{~Hz}$ ), 4.78-4.76 (1H, m), 3.51 (4H, brs), 2.33 (4H, brs), $2.20(3 \mathrm{H}, \mathrm{s}), 1.34(6 \mathrm{H}, \mathrm{d}, J=5.9 \mathrm{~Hz}) .{ }^{13} \mathrm{C}-\mathrm{NMR}(100 \mathrm{MHz}$, DMSO- $\left.d_{6}\right) \delta: 168.5,166.8,165.3,157.8,149.8,145.6,144.7$, $141.9,135.8,135.7,132.2,131.4,130.1,129.8,129.5,129.1$, $127.8,126.2,125.2,123.5,119.7,118.0,112.4,71.5,54.4,45.6$, 21.7. HR-MS (ESI-TOF) $m / z:[\mathrm{M}+\mathrm{H}]^{+}$Calcd for $\mathrm{C}_{31} \mathrm{H}_{33} \mathrm{~N}_{6} \mathrm{O}_{4} \mathrm{~S}$ 585.2284. Found 585.2295.

In Vitro TAK1 Enzyme Assay ${ }^{28)}$ For screening TAK1 inhibitors, insect expression vectors against GST-TAK1 and HisTAB1 were infected into insect cells. Then each tag-labeled kinase was purified using an anti-tag antibody-conjugated affinity column. Each purified kinase was mixed and used as an enzyme for screening. The kinase enzyme was incubated with various compounds and subsequently incubated with $6.25 \mu \mathrm{g}$ of myelin basic protein (Upstate Cat. 13-110) and $0.5 \mu \mathrm{Ci}$ of $\left[{ }^{33} \mathrm{P}\right] \mathrm{ATP}(3000 \mathrm{Ci} / \mathrm{mmol}$, GE Healthcare) in $50 \mu \mathrm{L}$ of the kinase buffer containing $25 \mathrm{~mm}$ Tris buffered saline (TBS) $(\mathrm{pH}$ 7.6), $0.5 \mathrm{~mm}$ dithiothreitol, $5 \mathrm{~mm} \mathrm{MgCl}_{2}, 0.0025 \%$ Tween 20 at $30^{\circ} \mathrm{C}$ for $30 \mathrm{~min}$. Then $10 \mu \mathrm{L}$ of $25 \%$ trichloroacetic acid was added into the reaction well and samples further incubated at $4^{\circ} \mathrm{C}$ for $30 \mathrm{~min}$. Acid-precipitated samples were separated by a glass filter and liquid scintillation cocktails were added. The radioactivity of ${ }^{33} \mathrm{P}$ incorporated into myelin basic protein was measured with a MicroBeta (PerkinElmer). The $\mathrm{IC}_{50}$ values of our designed compounds was calculated by XL-fit, a software to generate sigmoid curve, at seven different concentration $(0.01,0.033,0.1,0.33,1,3.3$, and $10 \mu \mathrm{M})$.

Expression and Purification of TAK1-TAB1 Fusion Protein for Crystallographic Structure Analysis The details of expression and purification of TAK1-TAB1 fusion protein for crystallographic structure analysis, and crystallization has already been reported. ${ }^{20)}$

Crystallization, Data Collection and Structure Determination The purified TAK1-TAB1 fusion protein samples were concentrated to $3 \mathrm{mg} / \mathrm{mL}$ with about $0.2 \mathrm{~mm}$ of each compound (2, 3, and 4), and crystallization was carried out by the hanging-drop vapor diffusion method at $20-21^{\circ} \mathrm{C}$. The reservoir solution consisted of $1.7-1.9 \mathrm{M}$ sodium potassium phosphate $(\mathrm{pH}$ 7.5-7.7). Crystals appeared and grew to full size within 4-6d. These crystals were soaked in a solution of $1.7-1.9 \mathrm{M}$ sodium potassium phosphate $(\mathrm{pH} 7.5-7.7)$ containing $20 \%$ glycerol as a cryoprotectant. X-Ray diffraction data from crystals of the complex formed from TAK1-TAB1 with compounds $\mathbf{2}, \mathbf{3}$, or $\mathbf{4}$ were collected at cryogenic temperatures by the synchrotron radiation sources and detectors shown in Supplementary Table 1.

The diffraction datasets were indexed, integrated, and scaled using $\mathrm{XDS}^{29)}$ and Aimless ${ }^{30)}$ for the complex of TAK1TAB1 with compound 2, and using XDS and Scala ${ }^{31)}$ for the complex of TAK1-TAB1 with compounds $\mathbf{3}$ and $\mathbf{4}$.

The structure was determined by molecular replacement with the program MolRep ${ }^{32)}$ using the published TAK1-TAB1 crystal structure (PDB code 2EVA), ${ }^{33}$ ) as a search model. Models were built with the program $\operatorname{Coot}^{34)}$ and refined with the program Refmac5. ${ }^{35)}$ The X-ray data collection and refinement statistics are shown in supplementary Table 1. Refined $\mathrm{X}$-ray coordinates and structure factors of TAK1-TAB1 in complex with compounds $\mathbf{2}, \mathbf{3}$, and $\mathbf{4}$ have been deposited in the PDB with accession codes 5GJD, 5GJF, and 5GJG, respectively.

Acknowledgment We thank Y. Furuta and M. Arai for HR-MS measurements.

Conflict of Interest The authors declare no conflict of interest.

Supplementary Materials The online version of this article contains supplementary materials. They include ${ }^{1} \mathrm{H}-\mathrm{NMR}$ spectrum of compounds 3-6 and 8-10, and X-ray data collection and refinement statistics. 


\section{References}

1) Manning G., Whyte D. B., Martinez R., Hunter T., Sudarsanam S., Science, 298, 1912-1934 (2002).

2) Müller S., Chaikuad A., Gray N. S., Knapp S., Nat. Chem. Biol., 11, 818-821 (2015)

3) Harrison S., Das K., Karim F., Maclean D., Mendel D., Expert Opinion on Drug Discovery, 3, 761-774 (2008)

4) Zhao Z., Wu H., Wang L., Liu Y., Knapp S., Liu Q., Gray N. S., ACS Chem. Biol., 9, 1230-1241 (2014).

5) Bollag G., Tsai J., Zhang J., Zhang C., Ibrahim P., Nolop K., Hirth P., Nat. Rev. Drug Discov., 11, 873-886 (2012).

6) Wenglowsky S., Ren L., Ahrendt K. A., Laird E. R., Aliagas I., Alicke B., Buckmelter A. J., Choo E. F., Dinkel V., Feng B., Gloor S. L., Gould S. E., Gross S., Gunzner-Toste J., Hansen J. D., Hatzivassiliou G., Liu B., Malesky K., Mathieu S., Newhouse B., Raddatz N. J., Ran Y., Rana S., Randolph N., Risom T., Rudolph J., Savage S., Selby L. T., Shrag M., Song K., Sturgis H. L., Voegtli W. C., Wen Z., Willis B. S., Woessner R. D., Wu W. I., Young W. B., Grina J., ACS Medicinal Chemistry Letters, 2, 342 (2011).

7) Zhao H., Caflisch A., Bioorg. Med. Chem. Lett., 24, 1523-1527 (2014).

8) Charnley A. K., Convery M. A., Lakdawala Shah A., Jones E., Hardwicke P., Bridges A., Ouellette M., Totoritis R., Schwartz B., King B. W., Wisnoski D. D., Kang J., Eidam P. M., Votta B. J., Gough P. J., Marquis R. W., Bertin J., Casillas L., Bioorg. Med. Chem., 23, 7000-7006 (2015).

9) Kwarcinski F. E., Brandvold K. R., Phadke S., Beleh O. M., Johnson T. K., Meagher J. L., Seeliger M. A., Stuckey J. A., Soellner M. B., ACS Chem. Biol., 11, 1296-1304 (2016).

10) Pan Z., Scheerens H., Li S. J., Schultz B. E., Sprengeler P. A., Burrill L. C., Mendonca R. V., Sweeney M. D., Scott K. C., Grothaus P. G., Jeffery D. A., Spoerke J. M., Honigberg L. A., Young P. R., Dalrymple S. A., Palmer J. T., ChemMedChem, 2, 58-61 (2007).

11) Yamaguchi K., Shirakabe K., Shibuya H., Irie K., Oishi I., Ueno N., Taniguchi T., Nishida E., Matsumoto K., Science, 270, 2008-2011 (1995)

12) Sakurai H., Trends Pharmacol. Sci., 33, 522-530 (2012).

13) Ninomiya-Tsuji J., Kishimoto K., Hiyama A., Inoue J., Cao Z., Matsumoto K., Nature (London), 398, 252-256 (1999).

14) Sato S., Sanjo H., Takeda K., Ninomiya-Tsuji J., Yamamoto M., Kawai T., Matsumoto K., Takeuchi O., Akira S., Nat. Immunol., 6, 1087-1095 (2005).

15) Shibuya H., Yamaguchi K., Shirakabe K., Tonegawa A., Gotoh Y., Ueno N., Irie K., Nishida E., Matsumoto K., Science, 272, 11791182 (1996)

16) Takaesu G., Kishida S., Hiyama A., Yamaguchi K., Shibuya H., Irie K., Ninomiya-Tsuji J., Matsumoto K., Mol. Cell, 5, 649-658 (2000).

17) Ishitani T., Takaesu G., Ninomiya-Tsuji J., Shibuya H., Gaynor R. B., Matsumoto K., EMBO J., 22, 6277-6288 (2003)

18) Adcock I. M., Chung K. F., Caramori G., Ito K., Eur. J. Pharmacol., 533, 118-132 (2006).

19) Courties G., Seiffart V., Presumey J., Escriou V., Scherman D., Zwerina J., Ruiz G., Zietara N., Jablonska J., Weiss S., Hoffmann
A., Jorgensen C., Apparailly F., Gross G., Blood, 116, 3505-3516 (2010)

20) Muraoka T., Ide M., Morikami K., Irie M., Nakamura M., Miura T. Kamikawa T., Nishihara M., Kashiwagi H., Bioorg. Med. Chem., 24, 4206-4217 (2016).

21) Liu Y., Gray N. S., Nat. Chem. Biol., 2, 358-364 (2006).

22) Okram B., Nagle A., Adrian F. J., Lee C., Ren P., Wang X., Sim T., Xie Y., Wang X., Xia G., Spraggon G., Warmuth M., Liu Y., Gray N. S., Chem. Biol., 13, 779-786 (2006).

23) Bollag G., Hirth P., Tsai J., Zhang J., Ibrahim P. N., Cho H., Spevak W., Zhang C., Zhang Y., Habets G., Burton E. A., Wong B., Tsang G., West B. L., Powell B., Shellooe R., Marimuthu A., Nguyen H., Zhang K. Y., Artis D. R., Schlessinger J., Su F., Higgins B., Iyer R., D’Andrea K., Koehler A., Stumm M., Lin P. S., Lee R. J., Grippo J., Puzanov I., Kim K. B., Ribas A., McArthur G. A., Sosman J. A., Chapman P. B., Flaherty K. T., Xu X., Nathanson K. L., Nolop K., Nature (London), 467, 596-599 (2010).

24) Huang X., Cheng C. C., Fischmann T. O., Duca J. S., Yang X., Richards M., Shipps G. W. Jr. ACS Medicinal, Chem. Lett., 3, 123 (2012).

25) Kilty I., Green M. P., Bell A. S., Brown D. G., Dodd P. G., Hewson C., Hughes S. J., Phillips C., Ryckmans T., Smith R. T., van Hoorn W. P., Cohen P., Jones L. H., Chem. Biol. Drug Des., 82, 500-505 (2013).

26) Tan L., Nomanbhoy T., Gurbani D., Patricelli M., Hunter J., Geng J., Herhaus L., Zhang J., Pauls E., Ham Y., Choi H. G., Xie T., Deng X., Buhrlage S. J., Sim T., Cohen P., Sapkota G., Westover K. D., Gray N. S., J. Med. Chem., 58, 183-196 (2015).

27) Tsai J., Lee J. T., Wang W., Zhang J., Cho H., Mamo S., Bremer R. Gillette S., Kong J., Haass N. K., Sproesser K., Li L., Smalley K. S., Fong D., Zhu Y. L., Marimuthu A., Nguyen H., Lam B., Liu J., Cheung I., Rice J., Suzuki Y., Luu C., Settachatgul C., Shellooe R., Cantwell J., Kim S. H., Schlessinger J., Zhang K. Y., West B. L., Powell B., Habets G., Zhang C., Ibrahim P. N., Hirth P., Artis D. R., Herlyn M., Bollag G., Proc. Natl. Acad. Sci. U.S.A., 105, 3041-3046 (2008).

28) Ninomiya-Tsuji J., Kajino T., Ono K., Ohtomo T., Matsumoto M. Shiina M., Mihara M., Tsuchiya M., Matsumoto K., J. Biol. Chem., 278, 18485-18490 (2003).

29) Kabsch W., Acta Crystallogr. D Biol. Crystallogr., 66, 125-132 (2010).

30) Evans P. R., Murshudov G. N., Acta Crystallogr. D Biol. Crystallogr., 69, 1204-1214 (2013).

31) Evans P., Acta Crystallogr. D Biol. Crystallogr., 62, 72-82 (2006)

32) Vagin A., Teplyakov A., Acta Crystallogr. D Biol. Crystallogr., 66, 22-25 (2010).

33) Brown K., Vial S. C., Dedi N., Long J. M., Dunster N. J., Cheetham G. M., J. Mol. Biol., 354, 1013-1020 (2005).

34) Emsley P., Lohkamp B., Scott W. G., Cowtan K., Acta Crystallogr. D Biol. Crystallogr., 66, 486-501 (2010).

35) Murshudov G. N., Skubak P., Lebedev A. A., Pannu N. S., Steiner R. A., Nicholls R. A., Winn M. D., Long F., Vagin A. A., Acta Crystallogr. D Biol. Crystallogr., 67, 355-367 (2011). 